World Lumen Congress 2021 | May 26-30, 2021 |

Iasi, Romania

\title{
Comparative Study regarding the Extracurricular Sports Activity among Primary and Middle Schoolers
}

\author{
Anca - Raluca TANASĂ, Cristina - Elena MORARU, \\ Petruț - Florin TROFIN, Rareş - Alexandru PUNI, \\ Răzvan - Andrei TOMOZEI
} https://doi.org/10.18662/wlc2021/63

How to cite: Tanasă, A.-R., Moraru, C.-E., Trofin, P.-F., Puni, R.-A., \& Tomozei, R.-A. (2021). Comparative Study regarding the Extracurricular Sports Activity among Primary and Middle Schoolers. In A. Sandu (vol. ed.), Lumen Proceedings: Vol. 17 World Lumen Congress 2021 (pp. 641-649). Iasi, Romania: LUMEN Publishing House. https://doi.org/10.18662/wlc2021/63 
Anca-Raluca TANASĂ, et al. | Lumen Proceedings 17 | WLC 2021

\title{
Comparative Study regarding the Extracurricular Sports Activity among Primary and Middle Schoolers
}

\author{
Anca - Raluca TANASĂ ${ }^{1}$, Cristina - Elena MORARU², \\ Petruț - Florin TROFIN ${ }^{3}$, Rareș - Alexandru PUNI', \\ RăZvan - Andrei TOMOZEI ${ }^{5}$
}

\begin{abstract}
The extracurricular sports activity among schooler children plays a significant role in the elimination of their sedentary behaviour. The purpose of this study was to analyse on a sample of 408 students aspects related to the following: the body mass index (BMI), the type of physical activities practiced, the parameters of the physical efforts made, the level of performance attained and the access to sports bases. The subjects within the research were divided into 4 groups: female primary schoolers (FP, $n=126,9.83 \pm 1.30$ years old), male primary schoolers (MP, $n=103$, $10,04 \pm 1.22$ years old), female middle schoolers (FM, $n=98,12.40 \pm 1.36$ years old) and male middle schoolers $(M M, n=81,12.22 \pm 1.33$ years old). The subjects underwent anthropometric and interrogative analyses, through the survey method. By using the Anova One $W$ ay $(p<0.05)$, we obtained significant differences of the BMI between FP- MM, MP-MM and $F M-M M$. The type of preferred sports activities differentiated $M P-M M$, the last group being centred on cyclical activities. The duration of the session presents significant differences between MP - FM. The weekly frequency and the annual durationof sports activity features a similar level. The volume of annual physical activities is differentiated between BP and FG. The performance level attained is different between MP - FM and MP - MM.
\end{abstract}

\footnotetext{
${ }^{1}$ Teaching Assistant, PhD Candidate, Faculty of Physical Education and Sport, "Alexandru Ioan Cuza” University of Iasi, Romania, ralucaatanasa@yahoo.com, 0751643227.

2 Assoc. Prof., PhD, Faculty of Physical Education and Sport, "Alexandru Ioan Cuza" University of Iasi, Romania, gimcristinamoraru@yahoo.com, 0744933133.

${ }^{3}$ Lecturer, PhD, Faculty of Physical Education and Sport, "Alexandru Ioan Cuza" University of Iasi

Centre of interdisciplinary research in the science of human motricity, Iasi, Romania, trofin.florin@uaic.ro, 0754288343.

${ }^{4}$ Lecturer, PhD, Faculty of Physical Education and Sport, "Alexandru Ioan Cuza" University of Iasi, Romania, punirares@yahoo.com, 0745460578.

5 Teaching Assistant, PhD Candidate, Faculty of Physical Education and Sport, "Alexandru Ioan Cuza” University of Iasi, Romania, andrei.tomozei@uaic.ro, 0743367922.
} 
Consequently, it may be stated that the preferences of schoolers regarding extracurricular sports activity are practiced with a frequency of 8 months per year, 3 times a week, each session lasting for 90 minutes, while their natureis cyclical at leisure level, too.

Keywords: extracurricular physical activity; students; evaluation; monitoring; sedentary behaviour.

\section{Introduction}

Physical activity is essential to the early development of any child and impacts many aspects of a child's health. Current health organizations argue that higher levels of physical activity in school-aged children are consistent with important short- and long-term health benefits in physical, emotional, social, and cognitive fields (King et al., 2003; Zeng, 2017).

Through this study we try to complete the subject of practicing physical effort outside the school program. Students in the Romanian education system have quite large deficiencies in the independent practice of physical exercise, resulting in a series of health problems that they may have throughout life. Thus, our contribution to the approached subject is given by the direct approach of the students through the survey and the highlighting of the aspects related to the possibility of the Romanian students to practice extracurricular sports activities (Lisinskiene \& Sukys, 2016).

Growth and development represent two processes particularising the first years within a person's life. They are influenced by the action of internal (genetic) and external factors (environmental). Environmental factors also include physical activity, diet and family. Systematic physical activity (a minimum of 60 minutes daily) leads to the enhancement of the cardiovascular, respiratory system and to the improvement in school performances. Among young people who exercise permanently, studies have reported better mental processes - planning, organisation, inhibition and memorising. Other studies highlight the improvement of the problemsolvingcapacity in math and the reading skills in young people who exercise systematically (Albu et al., 2020; Albu et al., 2018; Albu, et al., 2017; Chaddock et al., 2012; Haapala, 2013; Scudder et al., 2014). 4

Many factors have been pointed out as contributors to the current obesity epidemic. Years of inactivity, poor eating habits, and genetic factors have all played significant role. Nonetheless, the reality is that these factors may be only symptoms of more complex causes. Factors like supervised and restricted play, less recess, and overspecialized and highly competitive sports havecreated together an environment for children that promotes sedentary 
living and reduces physical activity (Bocarro et al., 2008; Hedley et al., 2004; Rosenfeld, 2004).

Certain authors argue that a physically active lifestyle during childhood is positively associated with brain and cognitive health. Anincreasing database of research pinpoints that aerobically fit children display higher academic achievement scores, higher cognitive performance, more efficient neuroelectric activation underlying attentional processes, and larger brain volumes in the hippocampus and basal ganglia than their less fit counterparts (Buck et al., 2008; Castelli et al., 2007; Chaddock et al., 2010a, 2010b,2011; 2012; Chomitz et al., 2009; Hillman et al., 2005, 2009; Kamijo et al., 2011; Pontifex, 2011; Sibley \& Etnier, 2003).

\section{Methods}

The aim of the research is to highlight the concerns of primary and secondary school students for extracurricular sports activities, as well as the way they carry them out. For this, we initiated a survey process of 408 students who met the criteria for integration into the study population we followed. The survey was conducted during January - April, 2021, the questionnaires being applied directly to each respondent. The analysis of the students involved was performed by comparing the answers according to age group and gender. Thus, they were divided into 4 groups: female primary schoolers ( $\mathrm{FP}, \mathrm{n}=126,9.83 \pm 1.30$ years), male primary schoolers $(\mathrm{BP}, \mathrm{n}=103,10.04 \pm 1.22$ years), female middle schoolers $(\mathrm{FG}, \mathrm{n}=98$, $12.40 \pm 1.36$ years) and male middle schoolers (BG, $\mathrm{n}=81,12.22 \pm 1.33$ years). The analyzed parameters were: the body mass index (BMI), the type of physical activities practiced, the parameters of the physical efforts made, the level of performance attained and the access to sports bases. Each qualitative response of the respondents was quantified in value in order to determine the differences between the analyzed parameters. In the questionnaires applied, subjects indicated the subjects practiced outside the school curriculum. Hence, after processing the data collected, each discipline was ascribed a number dependingon its motorpattern: 1 for cyclical sportsand 2 for the others. In addition, each student's practice levelwas noted with 1 for a leisure activityor with 2, for performance sport. Questions regarding perceived intensitywhile practicing the sports activities analysedand the degree of access to sporting bases provided a scale from 1 to 5 . Thus, values were directly proportional with the parameters studied.

Statistical analysis was performed by processing data using Graph Pad Prism 6. The results were compared through the Anova One-Way test, 
trying to observe the differences between boys and girls, but also between the two levels of education. The statistical results aimed to highlight the way in which extracurricular physical exercise is practiced by students. The significance level was set at 0.05 .

\section{Results}

By using the Anova One - Way $(\mathrm{p}<0.05)$, we obtained significant differences of the BMI between FP- BG, BP - BGand FG - BG. The type of preferred sports activities differentiated $B P-B G$, the last group being centred on cyclical activities. The duration of the session presents significant differences between BP - FG. The weekly frequency and the annual duration of sports activity features a similar level. The volume of annual physical activities is differentiated between BP and FG. The performance level attained is different between BP - FG and BP - BG. Table 1 featured the centralised data of the study

Table 1 - Study findings

\begin{tabular}{|c|c|c|c|c|c|}
\hline & FP & MP & FG & MG & $\mathrm{p}$ \\
\hline BMI (kg/m2) & $\begin{array}{l}18,21 \\
3,83\end{array}$ & $\begin{array}{l}18.53 \\
3.79\end{array}$ & $=\begin{array}{l}18.84 \\
4.09\end{array}$ & $\pm \begin{array}{l}21.70 \\
4.24\end{array}$ & $\pm<0.0001$ \\
\hline Sports activity type & $1.31 \pm 0.74$ & $1.38 \pm 0.76$ & $1.24 \pm 0.81$ & $1.05 \pm 0.74$ & 0.02 \\
\hline $\begin{array}{l}\text { Duration of a session } \\
\text { (min) }\end{array}$ & $\begin{array}{l}77.11 \\
59.92\end{array}$ & $\begin{array}{l}77.96 \\
58.87\end{array}$ & $=\mid \begin{array}{l}49.60 \\
49.81\end{array}$ & $\pm \begin{array}{l}65.44 \\
57.64\end{array}$ & $=0.0009$ \\
\hline $\begin{array}{l}\text { Weekly frequency } \\
\text { (no. } \\
\text { sessions/week) }\end{array}$ & $2,42 \pm 2.03$ & $2.85 \pm 2.16$ & $2.63 \pm 2.20$ & $2.82 \pm 2.50$ & 0.47 \\
\hline $\begin{array}{ll}\begin{array}{l}\text { Annual } \\
\text { (months) }\end{array} & \text { duration } \\
\end{array}$ & $7.89 \pm 4.81$ & $8.28 \pm 4.65$ & $7.16 \pm 5.12$ & $7.49 \pm 5.09$ & 0.40 \\
\hline $\begin{array}{l}\text { Annual } \\
(\mathrm{min})\end{array}$ & \begin{tabular}{|l}
8815 \\
11188 \\
\end{tabular} & $\begin{array}{l}14057 \\
31621 \\
\end{array}$ & $\begin{array}{l}6746 \\
8710\end{array}$ & $\begin{array}{r}10197 \\
15216 \\
\end{array}$ & $=0.05$ \\
\hline $\begin{array}{l}\text { Perceived intensity } \\
(1-5)\end{array}$ & $2.62 \pm 1.60$ & $2.80 \pm 1.66$ & $2.61 \pm 1.79$ & $2.62 \pm 1.81$ & 0.83 \\
\hline Performance level & $1.07 \pm 0.63$ & $1.15 \pm 0.68$ & $0.90 \pm 0.60$ & $0.90 \pm 0.62$ & 0.01 \\
\hline $\begin{array}{l}\text { Access to sporting } \\
\text { bases (1-5) }\end{array}$ & $1.69 \pm 1.42$ & $1.75 \pm 1.45$ & $1.63 \pm 1.30$ & $1.36 \pm 1.30$ & 0.23 \\
\hline
\end{tabular}


The study findings provide a view of the students' possibilities and habits (regarding the two study cycles). Body mass index features a statistical differentiation between the middle school boys and each of the other groups $(p<0.0001)$. Their value $-21.70 \pm 4.24 \mathrm{~kg} / \mathrm{m} Z_{1 \mathrm{~s}}$ higher than the others, which may be due to boys' higher body mass index during middle school. In what concerns the type of leisure physical activity, the difference is made between the two groups of boys $(\boldsymbol{p}=\mathbf{0 . 0 2})$ : primary school boys prefer noncyclical activities $(\mathbf{1 . 3 8} \pm \mathbf{0 . 7 6})$, but as they get older, they tend to choose subjects with a higher degree of repeatability regarding motor actions (basketball, football, gymnastics, swimming, horse-riding, dance sport, jogging, bike riding, outdoor physical activities, tennis, ballet, karate, kwan ki do, roller skating, taekwondo, kickboxing, fitness, fencing, etc). The duration of a sporting activity is different for middle school girls $\mathbf{( 4 9 . 6 0 \pm 4 9 . 8 1}$ minutes) and the two primary school groups. At the same time, there is a visible difference between the two age levels: older groups allocate less time to extracurricular physical activities. The number of weekly sporting activities is the same for all groups analysed, from $2.42 \pm 2.03$ (FP) to $2.82 \pm$ $2.50(M G)$. The same goes for the annual duration of independent sports practice: students are active 8 months on average. Whereas a differentiation would be expected in what concerns total annual estimated duration allocated to sports, the statistical significance of the Anova test is at the limit $(\boldsymbol{p}=\mathbf{0 . 0 5})$. Visually, greater average time is dedicated to sports activities by middle school students and by boys. Perceived intensity during a sporting activity is not differentiated by age levels or genders $(p=0.83)$; it is situated in the middle of the scale we outlined through the questionnaire. The performance level attained by our subjects reached a peak of $\mathbf{1 . 1 5} \pm \mathbf{0 . 6 8}$ $(M P)$, more than boys $(\mathbf{0 . 9 0} \pm \mathbf{0 . 6 2})$ and girls $(0.90 \pm \mathbf{0 . 6 0})$ in middle school. Access to sporting bases -with scores from 1 to 5 -is similar for the four groups, from $1.75 \pm 1.45$ down.

\section{Discussion}

The BMI of middle school boys - higher than the one of the other groups -is a warning sign concerning the importance of exercising for students; lack of exercising may entail negative modifications of health indicators. The group is different from the others in terms of a significantly higher body mass $(56.82 \pm 13.62)$. this led to an increase in the body mass index, even if the height s different, too. Preference for sporting subjects is different from one person to another, because the development environment may also have a contribution. In our case, only boys changed 
their option for sporting subject type, from dynamic to cyclical. This may be explained by the older age and the need to experience new sports. The time allocated to extracurricular motor activities is essential for good health. Middle school girls allocate less time to sports activities, less than the primary school girls. The difference is not significant compared to boys of the same age, which indicates less tie dedicated to exercising. The differences may be caused by the stuffed curriculum, the perceived pressure of high school admission, the technological temptations, etc. Whereas the values are close, the number of weekly sessions is 3 on average, while the activity spans across 7-8 months for all groups. The annual time volume dedicated to sorts is the same for all groups, with rather visible variations. The values reported show a higher level among boys, given their well-known appetite for moving. Perceived intensity during physical effort is average and above, which means that, despite the subjective appraisal, they are able to dose their effort depending on the individual capacity. Sports performance is a rather challenging ideal because it requires significant resources, which students do not possess. According to our subjects' reports, primary school boys have scored significantly higher than both middle school groups. This is probably related to the lower time volume dedicated to extracurricular sports activities. Sporting bases represent an important pillar of selection mass development for performance sport. Children within our study have restricted access to sports bases: they reached a maximum level of 3 , on the5-level scale we used. Hence, the other findings are not fortuitous: there is an interdependence between all aspects approached in our study.

\section{Conclusion}

Consequently, it may be stated that the preferences of primary and middle school students regarding extracurricular sports activities span across 8 months per year, three times a week, each session lasting 90 minutes on average. Their nature is cyclical and they are mainly leisure sports. In what regards preferences for sports subjects, they are different from one person to another: boys change their preferences from dynamic activities to cyclical activities. BMI is a warning sign on the importance of exercising for students (higher scores are recorded by boys). The annual volume of time dedicated to sports activities features rather high variations, but it is the same for all groups; boys recorded higher scores; perceived intensity was average or even above. Given that sports performance requires significant resources, many students do not have such resources, hence performance is a challenging 
ideal in terms of sports. Our study shows that access to sports bases is reduced: maximum level of 3 , on the5-level scale we used.

Hence, the other findings are not coincidental: there is an interconnection between all the aspects approached in this piece of research.

\section{Acknowledgements}

All authors have equally contributed to this paper.

We hereby express our gratitude to the subjects who participates in the study, to the Sports Selection and Counselling Centre Iaşi and to all the volunteers of this research.

\section{References}

Albu, A., Indrei L. L., \& Carausu, M. (2018). Caracteristici generale ale procesului de creştere şi dezvoltare al elevilor din ciclul primar [General characteristics of primary school children's growth and development]. In V. Mocanu (Ed.), Prevenția obezității la vârsta copilăriei-Cerealele integrale. Recomandări și bune practici [Prevention of childhood obesity - Whole grains. Recommendations and good practices]. (pp. 79-85). "Alexandru Ioan Cuza" University of Iasi Publishing House.

Albu, A., Onose, I., Carausu, E.M., Hodorca R.M. (2017). Appreciation of eating habits in a group of teenagers from two high schools in the city of Iasi: sports high school and G. Ibraileanu theoretical high school, DiscobolulPhysical Education, Sport and kinesiotherapy Joumal, 13(2), 19-23.

Albu, A., Petrariu, F. D., \& Onose, I. (2020). Physical Activity - Diet Correlation in a Sample of Teenagers within two High Schools in Romania (Sports and Theoretical High School). Interdisciplinary Journal of Physical Education and Sports, 20(1), 1-9. https://doi.org/10.36836/2020/1/7

Bocarro, J., Kanters, M., \& Casper, J., M. (2008). Schools Physical Education, Extracurricular Sports, and Lifelong Active Living. Journal of Teacbing in Physical Education, 27(2), 155-166. https://doi.org/10.1123/itpe.27.2.155

Buck, S. M., Hillman, C. H., \& Castelli, D. M. (2008). The relation of aerobic fitness to Stroop task performance in preadolescent children. Medicine and Science in Sports and Exercise, 40(1), 166-172. http://doi.org/10.1249/mss.0b013e318159b035

Castelli, D. M., Hillman, C. H., Buck, S. M., \& Erwin, H. E. (2007). Physical fitness and academic achievement in third- and fifth-grade students. Journal of Sport and Exercise Psychology, 29(2), 239-252.

https://doi.org/10.1123/isep.29.2.239

Chaddock, L., Erickson, K. I., Prakash, R. S., Kim, J. S., Voss, M. W., VanPatter, M., Pontifex, M. B., Raine, L. B., Hillman, C. H., Cohen, N. J., \& Kramer, 
A. F. (2010a). A neuroimaging investigation of the association between aerobic fitness, hippocampal volume and memory performance in preadolescent children. Brain Research, 1358, 172-183.

http://doi.org/10.1016/j.brainres.2010.08.049

Chaddock, L., Erickson, K. I., Prakash, R. S., VanPatter, M., Voss, M. V., Pontifex, M. B., Raine, L. B., \& Kramer, A. F. (2010b). Basal ganglia volume is associated with aerobic fitness in preadolescent children. Developmental Neuroscience, 32(3), 249-256. https://doi.org/10.1159/000316648

Chaddock, L., Hillman C., Pontifex, M., Johnson, C., Raine, L., \& Kramer A. (2012). Childhood aerobic fitness predicts cognitive performance on year later. Journal of Sports Sciences, 30(5), 421-430. http://doi.org/10.1080/02640414.2011.647706

Chaddock, L., Hillman, C. H., Buck, S. M., \& Cohen, N. J. (2011). Aerobic fitness and executive control of relational memory in preadolescent children. Medicine and Science in Sports and Exercise, 43(2), 344-349. http://doi.org/10.1249/MSS.0b013e3181e9af48

Chomitz, V. R., Slining, M. M., McGowan, R. J., Mitchell, S. E., Dawson, G. F., \& Hacker, K. A. (2009). Is there a relationship between physical fitness and academic achievement?. Positive results from public school children in the northeastern United States. Journal of School Health, 79(1), 30-37. https://doi.org/10.1111/j.1746-1561.2008.00371.x

Haapala, E. (2013). Cardiorespiratory fitness and motor skills relation to cognition and academic performance in children - a review. Journal of Human Kinetics, 36, 55-68. https://doi.org/10.2478/hukin-2013-0006

Hedley, A. A., Ogden, C. L., Johnson, C. L., Carroll, M. D., Curtin, L. R., Flegal, K. M. (2004). Prevalence of overweight and obesity among US children, adolescents, and adults, 1999- 2002. Journal of the American Medical Association, 291(23), 2847-2850. http://doi.org/10.1001/jama.291.23.2847

Hillman, C. H., Buck, S. M., Themanson, J. R., Pontifex, M. B., \& Castelli, D. M. (2009). Aerobic fitness and cognitive development: Event-related brain potential and task performance of executive control in preadolescent children. Developmental Psychology, 45(1), 114-129. https://doi.apa.org/doi/10.1037/a0014437

Hillman, C. H., Castelli, D.M., \& Buck, S.M. (2005). Aerobic fitness and neurocognitive function in healthy preadolescent children. Medicine and Science in Sports and Exercise, 37(11), 1967-1974. https://doi.org/10.1249/01.mss.0000176680.79702.ce

Kamijo, K., Pontifex, M. B., O’Leary, K. C., Scudder, M. R., Wu, C., Castelli, D. M. et al. (2011). The effects of an afterschool physical activity program on working memory in preadolescent children. Developmental Science, 14(5), 1046-1058. http://doi.org/10.1111/j.1467-7687.2011.01054.x 
King, G., Law, M., King, S., Rosenbaum, P., Kertoy, M. K., \& Young, N. L. (2003). A conceptual model of the factors affecting the recreation and leisure participation of children with disabilities. Physical \& Occupational Therapy in Pediatrics, 23(1), 63-90. https://doi.org/10.1080/J006v23n01 05

Lisinskiene, A., \& Sukys, S. (2016). Coach's role in encouraging parent-child educational interaction in sport. Global Journal of Sociology: Current Issues, 6(1), 1-8. http://doi.org/10.18844/gjs.v5i1.293

Pontifex, M. B., Raine, L. B., Johnson, C. R., Chaddock, L., Voss, M. W., Cohen, N. J., Kramer, A, F., \& Hillman, C. H. (2011). Cardiorespiratory fitness and the flexible modulation of cognitive control in preadolescent children. Journal of Cognitive Neuroscience, 23(6), 1332-1345. https://doi.org/10.1162/jocn.2010.21528

Rosenfeld, A. (2004). Harvard, soccer and over-scheduled families. Youth Studies Australia, 23(1), 15-18.

https://search.informit.org/doi/10.3316/ielapa.818383823569040

Scudder, M., Lambourne, K., Drollette, E., Herrmann, S., Washburn, R., Donnelly, J., \& Hillman, C. (2014). Aerobic Capacity and Cognitive Control in Elementary School-Age Children. Medicine \& Science in Sports \& Exercise, 46(5), 1025-1035. http://doi.org/10.1249/MSS.0000000000000199

Sibley, B. A., \& Etnier, J. L. (2003). The relationship between physical activity and cognition in children: A meta-analysis. Pediatric Exercise Science, 15(3), 243256. https://doi.org/10.1123/pes.15.3.243 